\title{
Sentiment Analysis Objek Wisata Kalimantan Barat Pada Google Maps Menggunakan Metode Naive Bayes
}

\author{
Ahmad Rifa' ${ }^{\# 1}$, Herry Sujaini*2, Dian Prawira ${ }^{\# 3}$

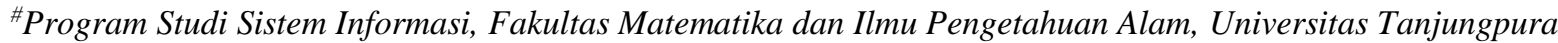 \\ Jl. Prof. Dr. H. Hadari Nawawi, Pontianak \\ 1ahmad.rifaidstudent.untan.ac.id \\ ${ }^{3}$ dianprawira@sisfo.untan.ac.id \\ *Program Studi Informatika, Fakultas Teknik, Universitas Tanjungpura \\ Jl. Prof. Dr. H. Hadari Nawawi, Pontianak \\ 2hseuntan.ac.id
}

\begin{abstract}
Abstrak - Kalimantan Barat merupakan salah satu provinsi di Indonesia yang pariwisatanya berpotensi untuk dikembangkan. Oleh karena itu, feedback dari wisatawan dibutuhkan untuk mengambil tindakan terkait pengembangan kualitas objek wisata Kalimantan Barat agar lebih optimal. Penelitian ini bertujuan untuk membangun sistem yang dapat melakukan sentiment analysis terhadap objek wisata di Kalimantan Barat berdasarkan data ulasan yang ada di Google Maps. Metodologi yang digunakan dalam penelitian ini adalah kerangka kerja IS Research Alan Hevner. Dalam melakukan riset sentiment analysis objek wisata Kalimantan Barat, metode yang digunakan untuk klasifikasi adalah Nä̈ve Bayes. Sebelum melakukan klasifikasi, dilakukan tahap pre-processing yang terdiri dari casefolding, tokenizing, filtering, stemming, dan tahap pembobotan kata menggunakan TF-IDF. Berdasarkan penelitian yang dilakukan, disimpulkan bahwa sistem dapat mengklasifikasikan kelas sentimen ulasan objek wisata yang terdapat pada Google Maps menggunakan metode Naive Bayes dengan nilai akurasi yang bervariasi dari setiap tempat wisata. Nilai akurasi tertinggi adalah 0,76 sedangkan terendah adalah 0,38 . Hasil sentimen analisis yang dilakukan pada objek wisata Kalimantan Barat masuk dalam kategori yang positif. Hal ini berdasarkan performa metode Naive Bayes yang menunjukan bahwa nilai rata-rata f1-score kelas positif adalah 0,73 lebih tinggi dibanding kelas netral 0,53 dan negatif 0.14
\end{abstract}

Kata kunci - Sentiment Analysis, Naive Bayes, PreProcessing, TF-IDF

\section{PENDAHULUAN}

Kalimantan Barat memiliki sektor pariwisata yang berpotensi untuk dikembangkan. Namun kurangnya promosi serta keterbukaan informasi terkait kualitas objek wisata di Kalimantan Barat menjadikan perkembangan objek wisata di Kalimantan Barat belum maksimal.
Saat ini keterbukaan informasi publik dapat terwujud berkat perkembangan ilmu pengetahuan dan teknologi. Salah satu contohnya adalah jasa peta daring yang mempunyai fitur untuk merencanakan sebuah rute serta mencari sebuah alamat atau yang dikenal dengan Google Maps. Di pertengahan tahun 2016 Google menambahkan fitur yang memungkinkan penggunanya untuk memberikan rating serta menambahkan ulasan pada tempat yang dikunjunginya [1].

Dari hasil pengamatan yang telah dilakukan, banyak pengunjung objek wisata Kalimantan Barat sudah memberikan ulasannya di Google Maps. Hal ini menjadi informasi yang berharga untuk meningkatkan kualitas pariwisata Kalimantan Barat. Dengan ulasan tersebut kita bisa melakukan analisa untuk menemukan sentimen apa yang diberikan oleh pengunjung.

Sentiment Analysis juga akrab dikenal sebagai opinion mining, merupakan sebuah area penelitian yang menganalisis opini publik, emosi, penilaian, sikap, dan sentimen tentang suatu objek seperti organisasi, produk, layanan, individu, peristiwa, masalah, dan topik [2].

Untuk melakukan sentiment analysis diperlukan sebuah metode, salah satuya Naïve Bayes. Dalam metode ini klasifikasi dilakukan dengan menghitung probabilitas. Naive Bayes memiliki keunggulan dalam efisiensi dan kesederhanaan pada pengklasifikasian teks, terutama dalam penerapan pada aplikasi praktis secara langsung seperti membagi kategori berita atau menyaring spam [3].

Dengan Sentiment Analysis, kita akan mendapatkan feedback yang cepat dari wisatawan dengan memanfaatkan ulasan yang telah mereka berikan sehingga stakeholder yang terlibat dapat mengambil tindakan langkah apa yang harus dilakukan kedepannya agar kualitas pariwisata di Kalimantan Barat dapat lebih berkembang secara optimal.

Terdapat beberapa kajian penelitian terdahulu yang dianggap relevan dengan tema penelitian ini. Adapun 
beberapa diantaranya penelitian [4] meningkatkan akurasi pada sistem klasifikasi pesan pengaduan RSUD Majalengka dari $75 \%$ berdasarkan kelas bidang menjadi $90 \%$ dan $75 \%$ berdasarkan kelas sentimen menjadi $100 \%$. Kemudian penelitian [5] menggunakan metode naive bayes classifier dengan pengujian 10-fold cross validation menunjukkan akurasi sebesar 96,5\% untuk Lazada, 93,9\% untuk Bukalapak dan 90,3\% untuk Bibli.com Lalu penelitian [6] dengan menggunakan metode Multinominal Naive Bayes dengan k-fold cross validation menghasilkan akurasi sebesar $71.60 \%, 70.72 \%$ dan $70,68 \%$. Kemudian penelitian [7] penggunaan dataset $20 \%$ data uji dan $80 \%$ data latih pada pengujian 5 kelas menghasilkan nilai akurasi terendah 52,66\%. Sedangkan penggunaan dataset $10 \%$ data uji dan $90 \%$ data latih pada pengujian 3 kelas menghasilkan akurasi tertinggi sebesar $77.78 \%$. Selanjutnya penelitian [8] melakukan analisis sentimen terkait tempat wisata di Tegal dan sekitarnya. Penelitian tersebut menunjukkan perbandingan akurasi Decision Tree lebih rendah dari Naïve Bayes dengan nilai $60,83 \%$ berbanding $77,50 \%$.

\section{METODE}

Penelitian ini memiliki perencanaan sistematis dan ilmiah yang mengadopsi model kerangka kerja IS Research Alan Hevner. Metode penelitian tersebut diilustrasikan pada Gambar 1 yang menunjukkan proses penelitian secara umum.

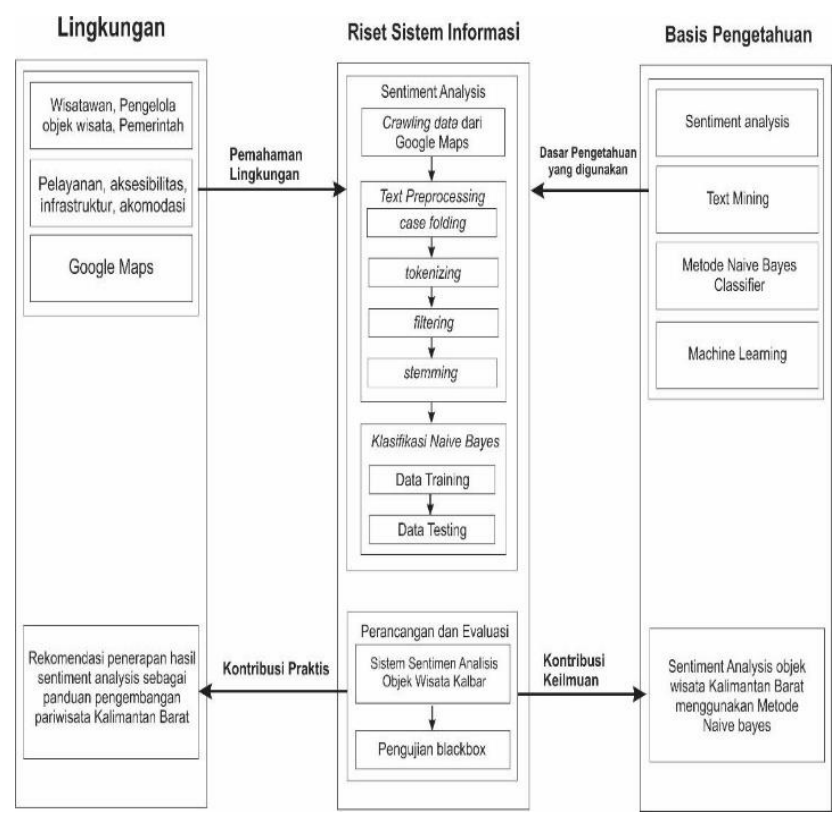

Gambar 1. Kerangka kerja penelitian

Penjelasan mengenai metode penelitian pada Gambar 1 yang mencakup isi dari ruang lingkup penelitian dijabarkan sebagai berikut:

\section{A. Lingkungan}

Target orang yang dianggap relevan dengan tujuan penelitian ini diantaranya adalah wisatawan, pengelola tempat wisata, dan pemerintah. Lalu dalam proses organisasi yang menjadi target tujuan adalah pelayanan, aksesibilitas, infrastruktur, serta akomodasi. Dan teknologi yang menjadi target tujuan adalah Google Maps.

\section{B. Riset Sistem Informasi}

Untuk melakukan sentimen analisis dimulai dengan crawling data dari Google Maps menggunakan Google Maps API. Untuk menggunakan Google Maps API diperlukan sebuah kode unik yang sudah diberikan oleh Google. Kode tersebut secara umum dikenal dengan API Key. API key digunakan agar sebuah website dapat dikenali oleh server Google Maps. [9].

Kemudian dilakukan text pre-processing meliputi case folding, tokenizing, filtering, dan stemming. Text preprocessing dilakukan agar suatu teks menjadi terstruktur dari sebelumnya [5].

Setelah itu dilakukan pembobotan kata dengan TF-IDF. TF-IDF merupakan sebuah metode yang digunakan untuk pembobotan kata (term weighting) dengan menghitung jumlah kemunculan setiap kata dalam suatu dokumen(TF), dan menghitung jumlah kemunculan kata dalam seluruh dokumen (IDF) [10].

$$
i d f_{t}=\ln \left(\frac{N}{d f_{t}}\right)+1
$$

Keterangan :

$i d f_{t} \quad=$ Nilai Invers document frequency

$N \quad=$ Jumlah keseluruhan dokumen

$d f_{t} \quad=$ Jumlah dokumen yang kata $t$

$$
t f i d f_{t}=t f_{t} X i d f_{t}
$$

Keterangan :

$t$ fid $f_{t}=$ Nilai $T F-I D F$

$t f_{t} \quad=\sum$ keseluruhan kata dalam dokumen

$i d f_{t} \quad=$ Nilai Invers document frequency

Setelah itu diklasifikasikan menggunakan metode Nä̈ve Bayes.

$V_{N B}=\operatorname{avgmax} P\left(v_{j}\right) \in V \prod_{i} P\left(a_{i} \mid v_{j}\right) P\left(v_{j}\right)$

Keterangan :

$v_{j}$ : Kategori opini dari $\mathrm{j}=1,2, \ldots, \mathrm{n}$.

$P\left(a_{i} \mid v_{j}\right)$ : Probabilitas $a_{i}$ pada kategori $v_{j}$

$P\left(v_{j}\right) \quad:$ Probabilitas dari $v_{j}$

Hasil akhir dari riset sistem informasi ini adalah sebuah sistem yang mampu melakukan sentimen analisis dan mengklasifikasikan sentimennya. Web menjadi basis dari sistem sentiment analisis, bahasa pemrograman python digunakan untuk melakukan pengolahan data dan bahasa pemrograman PHP digunakan untuk membangun website dengan menggunakan Laravel sebagai framework, serta MySQL sebagai database nya. Pada tahap akhir penelitian akan dilakukan pengujian performa naive bayes menggunakan confusion matrix. Confusion matrix juga dikenal dengan error matrix yaitu sebuah metode yang memungkinkan memvisualisasikan suatu kinerja algoritma, 
salah satunya adalah supervised learning [11]. Setiap kolom dari matriks merepresentasikan prediksi dari setiap kelas atau predicted class, sementara setiap baris merepresentasikan kelas sebenarnya actual class [12] (lihat Tabel 1).

TABEL I

CONFUSION MATRIX

\begin{tabular}{|c|c|c|c|}
\hline \multicolumn{2}{|c|}{} & \multicolumn{2}{|c|}{ Prediction Class } \\
\cline { 3 - 4 } \multicolumn{2}{|c|}{} & Positve & Negative \\
\hline \multirow{2}{*}{$\begin{array}{c}\text { Actual } \\
\text { Class }\end{array}$} & Positive & $T P$ & $F N$ \\
\cline { 2 - 4 } & Negative & $F P$ & $T N$ \\
\hline
\end{tabular}

Setelah mendapatkan nilai untuk masing-masing kelas, selanjutnya menghitung nilai akurasi, presisi, recall, dan fl-score. Adapun persamaannya dapat dilihat pada persamaan berikut ini :

$$
\begin{array}{r}
\text { Akurasi }=\frac{T P+T N}{T P+F P+T N+F N} \\
\text { Presisi }=\frac{T P}{T P+F P} \\
\text { Recall }=\frac{T P}{T P+F N} \\
f 1-\text { score }=2 \frac{\text { Precision } X \text { Recall }}{\text { Precision }+ \text { Recall }}
\end{array}
$$

Adapun teknik yang dipakai untuk pengujian fungsionalitas sistem dilakukan dengan menggunakan teknik blackbox.

\section{Basis Pengetahuan}

Secara garis besar, basis pengetahuan yang digunakan dalam penelitian ini adalah teori-teori mengenai text mining, sentiment analisis, machine learning, metode Naïve bayes serta teori pendukung lainnya.

Text Mining dijabarkan secara umum sebagai proses penggalian pengetahuan mendalam antara kumpulan dokumen secara berkala dari waktu ke waktu dengan penguna memakai seperangkat alat analisis. Text mining sebagian besar mengarah pada bidang penelitian data mining. Oleh sebab itu, text mining dan data mining akan berada pada tingkat arsitektur yang sama [10].

Naïve Bayes Classifier adalah sebuah metode untuk pengklasifikasian dengan peluang sederhana yang mengaplikasikan Teorema Bayes dengan hipotesis ketidakterikatan yang tinggi [13].

Machine Learning adalah kecakapan komputer untuk melakukan pelatihan tanpa harus menjabarkan secara spesifik kepada komputer [14]. Algoritma machine learning dapat dikategorikan berdasarkan masukan dan keluaran yang diharapkan dari algoritma.

\section{HASIL DAN PEMBAHASAN}

\section{A. Perancangan Sistem}

Perancangan sistem dilakukan untuk memberikan gambaran sistem yang akan dibangun.
1) Use Case Diagram: Interaksi fungsi-fungsi di dalam sistem dengan aktor digambarkan dalam use case diagram [15]. Use case diagram dari SAWi dapat dilihat pada Gambar 2.

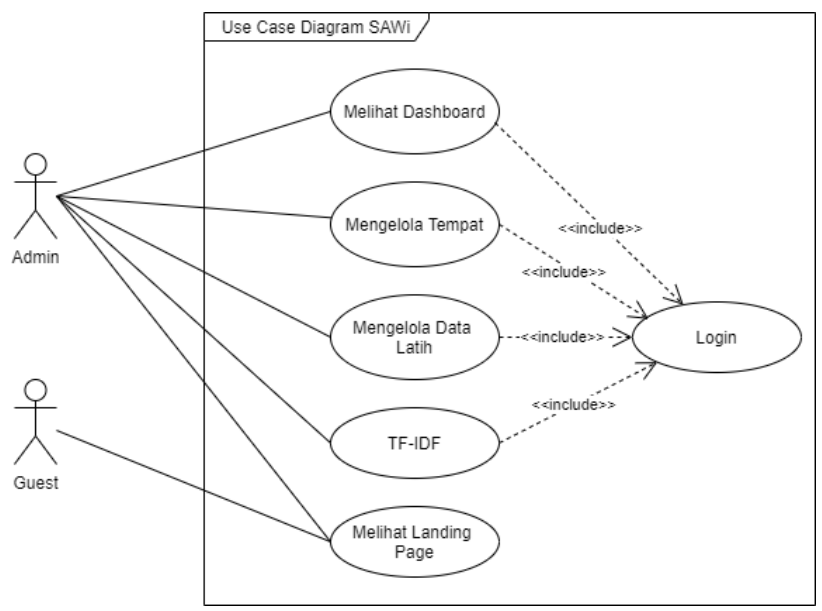

Gambar 2. Use Case diagram umum sistem

Use Case diagram terdiri dari melihat dashboard, mengelola tempat, mengolah data latih, TF-IDF, dan melihat landing page yang dapat diakses oleh 2 aktor yaitu admin sebagai pengelola dan guest sebagai pengguna umum yang hanya dapat landing page.

2) Activity Diagram: Diagram ini menunjukkan aliran..kerja..dari suatu sistem..atau.proses bisnis [15]. Gambaran umum mengenai activity diagram Gambar 3 terjadi antara aktor guest, sistem, dan aktor admin.

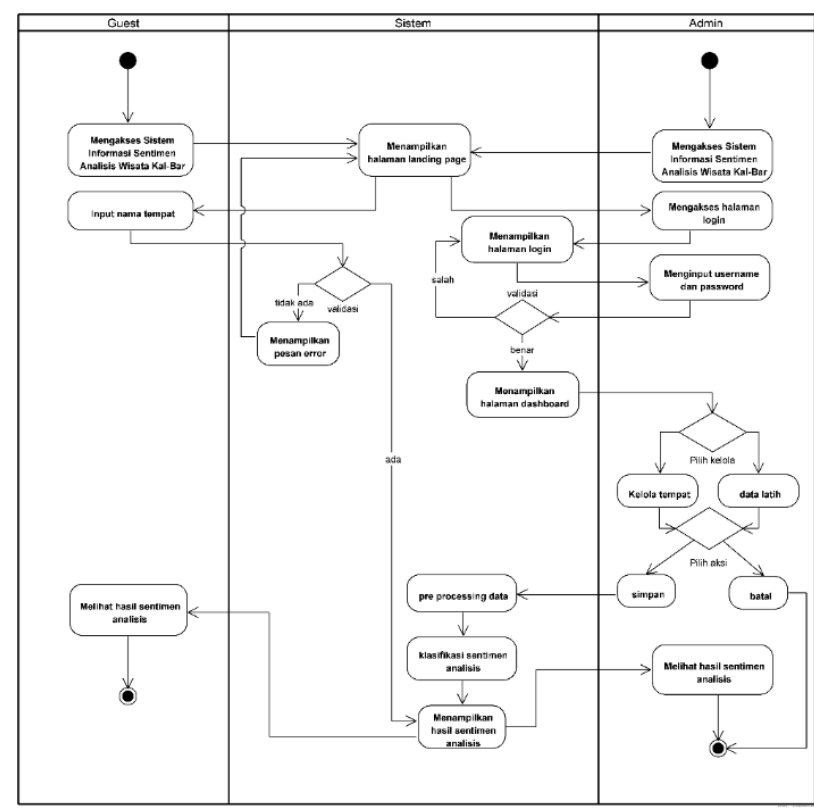

Gambar 3. Activity Diagram

Aktor guest dapat mengakses sistem sebagai pengguna umum untuk mendapatkan informasi sentimen tempat wisata hanya dari halaman landing page yang ditampilkan 
oleh sistem. Sedangkan aktor admin dapat mengakses sistem secara penuh sebagai pengelola sistem untuk mengolah informasi sentimen tempat wisata, deng halaman menu yang ditampilkan oleh sistem.

3) Squence Diagram: Sequence Diagram adalah suatu diagram yang menjelaskan perilaku objek pada use case dan menunjukkan komunikasi antara objek-objek tersebut [15]. Sequence.diagram mengimpor data tempat pada gambar 4 merupakan salah satu contoh dari sequence diagram yang terdapat pada Sistem Informasi Sentimen Analisis Objek Wisata Kal-Bar.

4) Class Diagram: Dalam sebuah sistem hubungan antar kelas digambarkan dengan class diagram [15]. Pada gambar 5 sistem ini terdapat 6 controller, yaitu dashboard, data latih, user, tempat, ulasan, dan tfidf.

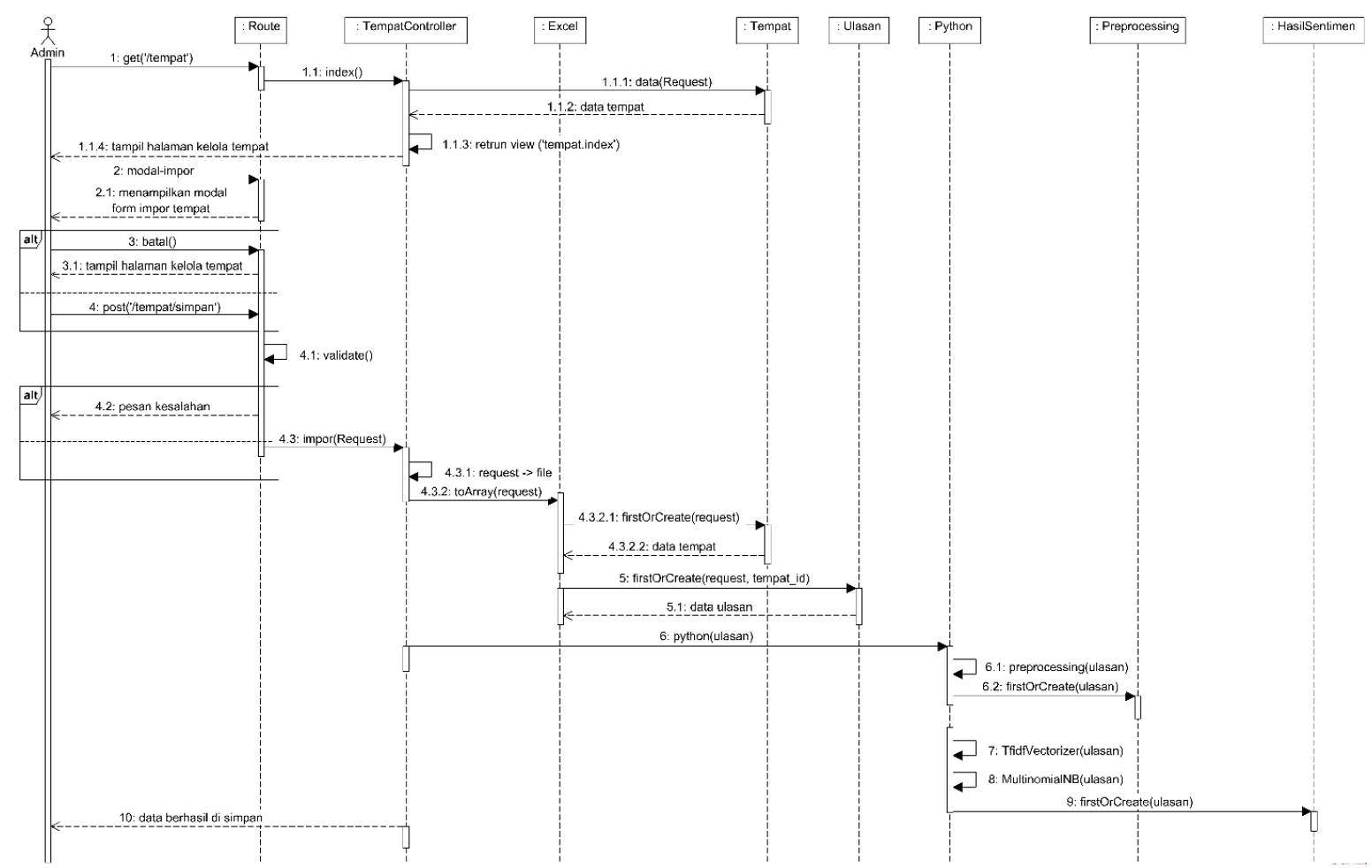

Gambar 4. Sequence Diagram impor tempat

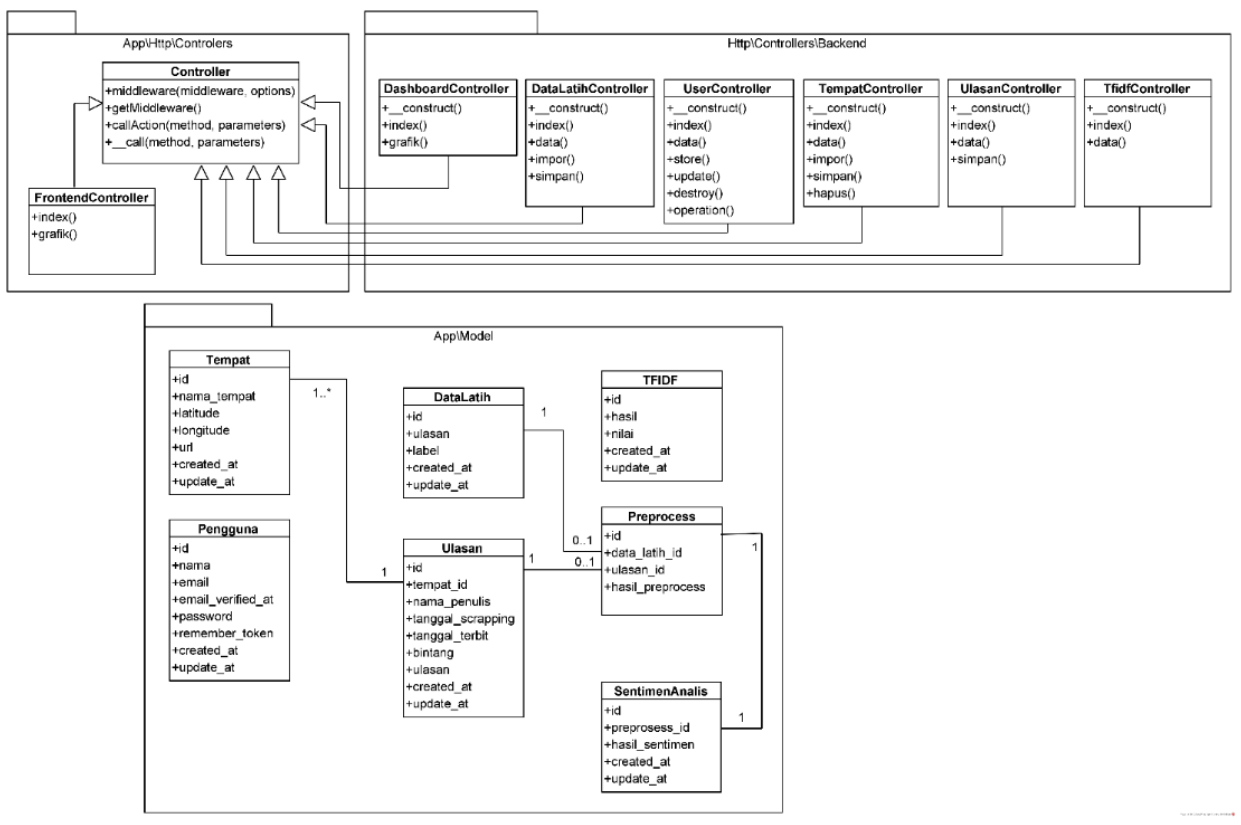

Gambar 5. Class Diagram 
5) Entity Relationship Diagram: Rancangan basis data dan hubungan antar entitas dalam sistem yang akan dibangun digambarkan dalam diagram ini [16]. Pada gambar 6 menunjukkan bahwa sistem ini terdapat tujuh entitas antara lain, pengguna, tempat, data latih, ulasan, preprocess, sentimen analisis, dan tfidf. Di dalam setiap entitas memiliki atribut, tipe data, serta memiliki relasi satu sama lain.

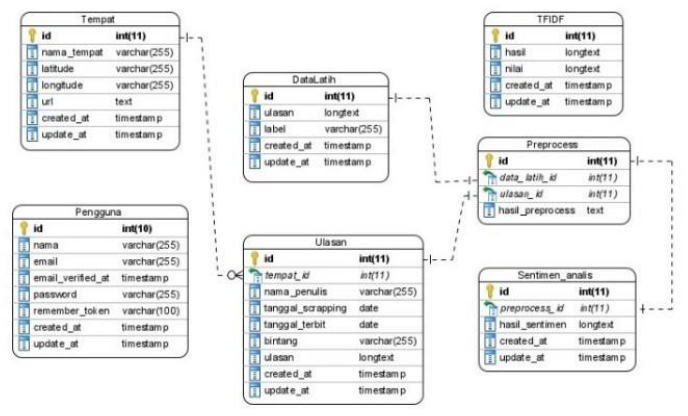

Gambar 6. Entity Relationship Diagram

\section{B. Perancangan Antarmuka}

Perancangan antarmuka berhubungan dengan tampilan dan interaksi yang akan mempermudah pengguna dalam penggunaan sistem. Adapun perancangan antarmuka yang akan dibangun pada sistem ini adalah sebagai berikut:

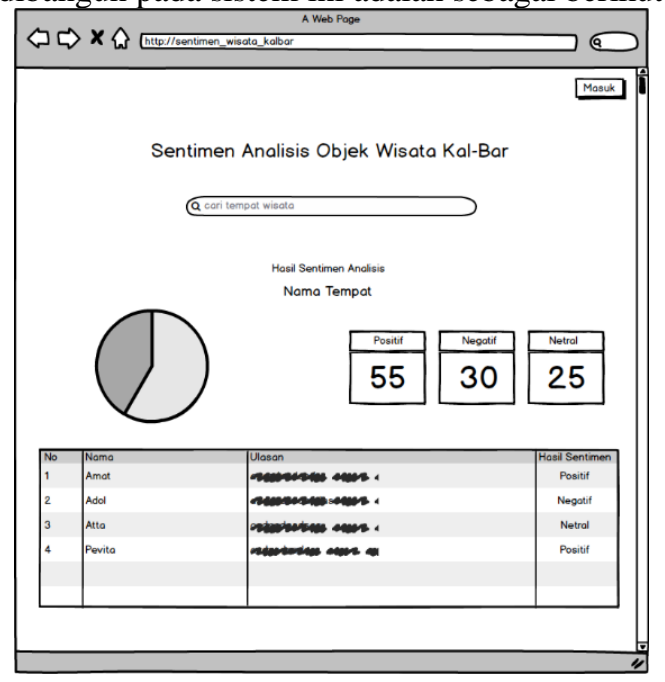

Gambar 6. Perancangan antarmuka landing page

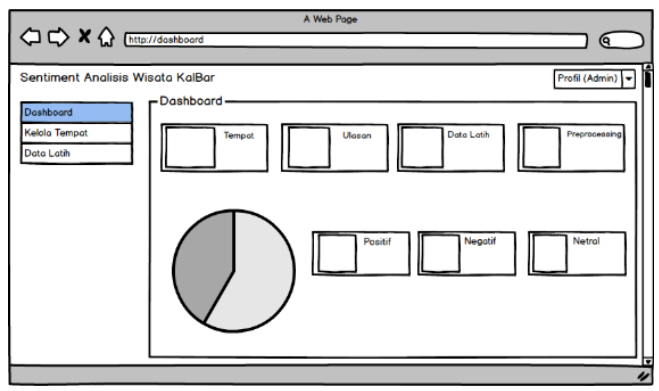

Gambar 7. Perancangan antarmuka dashboard

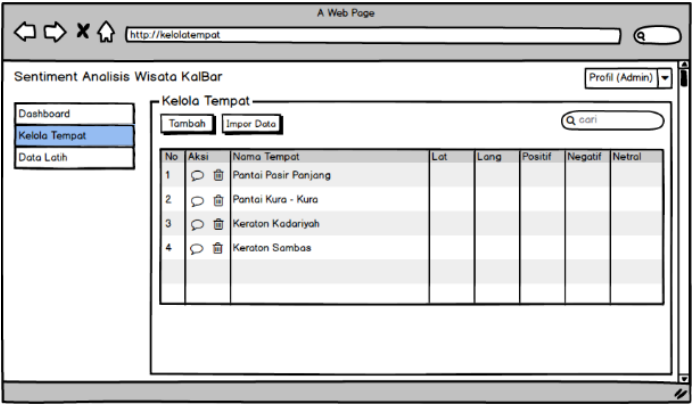

Gambar 8. Perancangan antarmuka kelola tempat

\section{Implementasi Antarmuka}

Hasil rancangan antarmuka yang telah dibuat diterapkan ke dalam sistem. Berikut ini adalah penerapan implementasi antarmuka pada sistem :

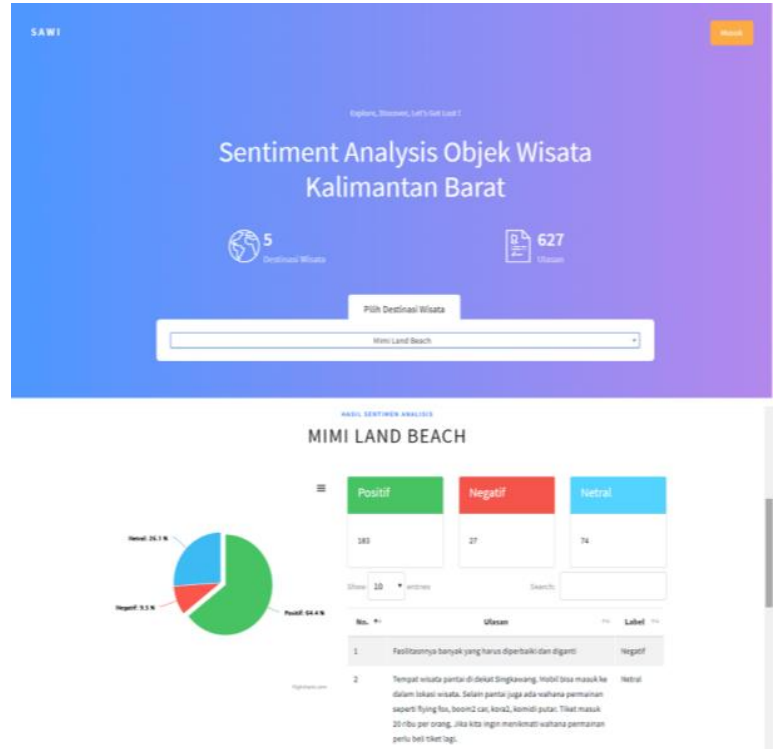

Gambar 9. Implementasi antarmuka landing page

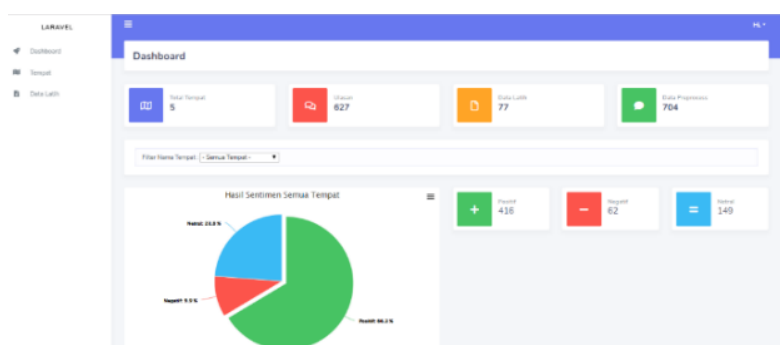

Gambar 10. Implementasi antarmuka dashboard

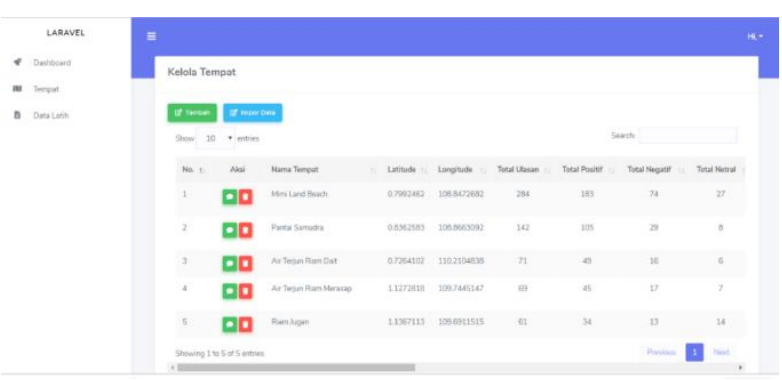

Gambar 11. Implmentasi antarmuka kelola tempat 


\section{Pengujian Confusion Matrix}

Sistem melakukan analisis sentimen pada data uji terhadap 10 tempat wisata di wilayah Kalimantan Barat dengan 50 ulasan setiap tempat. Berdasarkan hasil pengujian klasifikasi Naive Bayes dengan confusion matrix,

dari masing masing tempat objek wisata berbeda - beda Tabel 2 merupakan hasil pengujian klasifikasi Naive Bayes dengan confusion matrix terhadap 10 tempat objek wisata dapat dilihat bahwa akurasi, presisi, recall, dan f1-score

Kalimantan Barat.

TABEL II

HASIL PENGUJIAN DENGAN CONFUSION MATRIX

\begin{tabular}{|c|l|c|c|c|c|c|c|c|c|c|c|}
\hline \multirow{2}{*}{ No. } & Nama Tempat & Akurasi & \multicolumn{3}{|c|}{ Presisi } & \multicolumn{3}{c|}{ Recall } & \multicolumn{3}{c|}{$f$-1 Score } \\
\hline & Positif & Negatif & Netral & Positif & Negatif & Netral & Positif & Negatif & Netral \\
\hline 1. & $\begin{array}{l}\text { Wisata Air } \\
\text { Terjun Pancur } \\
\text { Aji }\end{array}$ & 0,76 & 0,91 & 0 & 0,69 & 0,74 & 0 & 0,86 & 0,82 & 0 & 0,77 \\
\hline 2. & $\begin{array}{l}\text { Taman Nasional } \\
\text { Danau Sentarum }\end{array}$ & 0,70 & 0,88 & 0,25 & 0,55 & 0,66 & 1,0 & 0,79 & 0,75 & 0,40 & 0,65 \\
\hline 3. & $\begin{array}{l}\text { Air Terjun Riam } \\
\text { Dait }\end{array}$ & 0,70 & 0,82 & 0 & 0,74 & 0,64 & 0 & 0,85 & 0,72 & 0 & 0,79 \\
\hline 4. & $\begin{array}{l}\text { Pantai Pasir } \\
\text { Panjang }\end{array}$ & 0,66 & 0,80 & 0,29 & 0,54 & 0,86 & 0,29 & 0,47 & 0,83 & 0,29 & 0,50 \\
\hline 5. & $\begin{array}{l}\text { Mempawah } \\
\text { Mangrove Park }\end{array}$ & 0,66 & 0,85 & 0,20 & 0,27 & 0,76 & 0,50 & 0,30 & 0,81 & 0,28 & 0,28 \\
\hline 6. & $\begin{array}{l}\text { Pantai Temajuk } \\
\text { Sambas }\end{array}$ & 0,64 & 0,93 & 0 & 0,47 & 0,63 & 0 & 0,70 & 0,75 & 0 & 0,56 \\
\hline 7. & $\begin{array}{l}\text { Bukit Kelam } \\
\text { Sintang }\end{array}$ & 0,64 & 0,95 & 0 & 0,57 & 0,61 & 0 & 0,71 & 0,74 & 0 & 0,63 \\
\hline 8. & $\begin{array}{l}\text { Air Terjun Riam } \\
\text { Pangar }\end{array}$ & 0,62 & 0,85 & 0,33 & 0,35 & 0,64 & 0,50 & 0,58 & 0,73 & 0,40 & 0,44 \\
\hline 9. & $\begin{array}{l}\text { Pantai Pulau } \\
\text { Datok }\end{array}$ & 0,56 & 0,95 & 0 & 0,32 & 0,53 & 0 & 0,70 & 0,68 & 0 & 0,44 \\
\hline 10. & $\begin{array}{l}\text { Tugu } \\
\text { Khatulistiwa } \\
\text { Pontianak }\end{array}$ & 0,38 & 0,65 & 0,05 & 0,54 & 0,50 & 0,33 & 0,28 & 0,56 & 0,087 & 0,37 \\
\hline
\end{tabular}

\section{E. Pengujian Fungsionalitas}

Tabel 3 merupakan hasil pengujian fungsionalits sistem menggunakan teknik blackbox

TABEL III

HASIL PENGUJIAN FUNGSIONALITAS SISTEM

\begin{tabular}{|c|l|l|l|c|}
\hline No. & \multicolumn{1}{|c|}{ Kelas Uji } & \multicolumn{1}{|c|}{ Pengujian } & \multicolumn{1}{c|}{ Keluaran Yang Diharapkan } & Kesimpulan \\
\hline 1. & $\begin{array}{l}\text { Pengujian halaman } \\
\text { landing page }\end{array}$ & $\begin{array}{l}\text { Pengguna mengakses SAWi melalui } \\
\text { url } \text { : https://sawi.zethlabs.id }\end{array}$ & $\begin{array}{l}\text { Pengguna dapat mengakses halaman } \\
\text { landing page }\end{array}$ & Berhasil \\
\hline 2. & $\begin{array}{l}\text { Pengujian fungsi } \\
\text { login }\end{array}$ & $\begin{array}{l}\text { Pengguna menginputkan } \text { email } \text { atau } \\
\text { username beserta password nya }\end{array}$ & $\begin{array}{l}\text { Sistem menampilkan halaman } \\
\text { dashboard dan pengguna berhasil } \\
\text { mengakses sistem }\end{array}$ & Berhasil \\
\hline 3. & $\begin{array}{l}\text { Pengujian halaman } \\
\text { dashboard }\end{array}$ & $\begin{array}{l}\text { Pengguna mengakses halaman } \\
\text { dashboard dengan memilih menu } \\
\text { dashboard pada side bar }\end{array}$ & $\begin{array}{l}\text { Sistem menampilkan halaman } \\
\text { dashboard }\end{array}$ & Berhasil \\
\hline 5. & $\begin{array}{l}\text { Pengujian halaman } \\
\text { data tempat }\end{array}$ & $\begin{array}{l}\text { Pengguna mengakses halaman tempat } \\
\text { dengan memilih menu tempat pada side } \\
\text { bar }\end{array}$ & $\begin{array}{l}\text { Sistem menampilkan halaman data } \\
\text { tempat }\end{array}$ & Berhasil \\
\hline tambah tempat & $\begin{array}{l}\text { Pengujian fungsi } \\
\text { impor tempat }\end{array}$ & $\begin{array}{l}\text { Pengguna memilih aksi tambah data } \\
\text { form modal menginputkan data tempat pada } \\
\text { tempat, memilih berkas yang akan } \\
\text { diimpor }\end{array}$ & $\begin{array}{l}\text { Pengguna berhasil menambahkan } \\
\text { data tempat dan sistem menampilkan } \\
\text { pesan berhasil }\end{array}$ & Berhasil \\
\hline 7. & $\begin{array}{l}\text { Pengujian halaman } \\
\text { lihat ulasan }\end{array}$ & $\begin{array}{l}\text { Pengguna memilih aksi lihat ulasan sistem menampilkan } \\
\text { tempat, pilih tempat objek wisata yang } \\
\text { akan dilihat ulasannya }\end{array}$ & $\begin{array}{l}\text { Sistem menampilkan halaman lihat } \\
\text { ulasan tempat objek wisata }\end{array}$ & Berhasil \\
\hline
\end{tabular}




\begin{tabular}{|c|l|l|l|c|}
\hline No. & \multicolumn{1}{|c|}{ Kelas Uji } & \multicolumn{1}{|c|}{ Pengujian } & \multicolumn{1}{c|}{ Keluaran Yang Diharapkan } & Kesimpulan \\
\hline 8. & $\begin{array}{l}\text { Pengujian fungsi } \\
\text { hapus tempat }\end{array}$ & $\begin{array}{l}\text { Pengguna memilih aksi hapus data } \\
\text { tempat, pilih tombol konfirmasi hapus } \\
\text { data tempat }\end{array}$ & $\begin{array}{l}\text { Pengguna berhasil menghapus data } \\
\text { tempat dan sistem menampilkan } \\
\text { pesan berhasil }\end{array}$ & Berhasil \\
\hline 9. & $\begin{array}{l}\text { Pengujian halaman } \\
\text { data latih }\end{array}$ & $\begin{array}{l}\text { Pengguna mengakses halaman data latih, } \\
\text { memilih menu data latih pada side bar }\end{array}$ & $\begin{array}{l}\text { Sistem menampilkan halaman data } \\
\text { latih }\end{array}$ & Berhasil \\
\hline 10. & $\begin{array}{l}\text { Pengujian fungsi } \\
\text { tambah data latih }\end{array}$ & $\begin{array}{l}\text { Pengguna memilih aksi tambah data } \\
\text { latih, menginputkan data latih pada form } \\
\text { modal tambah data latih }\end{array}$ & $\begin{array}{l}\text { Pengguna berhasil menambahkan } \\
\text { data latih dan sistem menampilkan } \\
\text { pesan berhasil }\end{array}$ & Berhasil \\
\hline 11. & $\begin{array}{l}\text { Pengujian fungsi } \\
\text { impor data latih }\end{array}$ & $\begin{array}{l}\text { Pengguna memilih aksi impor data latih, } \\
\text { pilih berkas yang akan diimpor }\end{array}$ & $\begin{array}{l}\text { Pengguna berhasil mengimpor data } \\
\text { latih dan sistem menampilkan pesan } \\
\text { berhasil }\end{array}$ & Berhasil \\
\hline 12. & $\begin{array}{l}\text { Pengujian fungsi } \\
\text { edit data latih }\end{array}$ & $\begin{array}{l}\text { Pengguna memilih aksi edit data latih, } \\
\text { menginput kan data terbaru pada data } \\
\text { latih yang akan diubah pada form modal } \\
\text { edit data latih }\end{array}$ & $\begin{array}{l}\text { Pengguna berhasil melakukan edit } \\
\text { data latih dan sistem menampilkan } \\
\text { pesan berhasil }\end{array}$ & Berhasil \\
\hline 13. & $\begin{array}{l}\text { Pengujian fungsi } \\
\text { hapus data latih }\end{array}$ & $\begin{array}{l}\text { Pengguna memilih aksi hapus data latih, } \\
\text { pilih tombol konfirmasi hapus data latih }\end{array}$ & $\begin{array}{l}\text { Pengguna berhasil menghapus data } \\
\text { latih dan sistem menampilkan pesan } \\
\text { berhasil }\end{array}$ & Berhasil \\
\hline
\end{tabular}

\section{F. Pengujian Antarmuka}

Berdasarkan hasil pengujian antarmuka sistem terhadap 40 responden yang dianalisis menggunakan perhitungan skala likert sistem yang dibangun mendapatkan nilai 84,85\% dan masuk kedalam rentang kategori baik sekali

\section{KESIMPULAN}

Dari hasil penelitian dengan judul Sentiment Analysis Objek Wisata Kalimantan Barat Pada Google Maps Menggunakan Metode Naive Bayes yang sudah dilakukan dapat ditarik kesimpulan sebagai berikut :

1. Sistem Sentiment Analysis Objek Wisata Kalimantan Barat dapat mengklasifikasikan kelas sentimen ulasan objek wisata yang terdapat pada Google Maps menggunakan metode Naive Bayes. Hasil ulasan yang telah diklasifikasikan oleh sistem ditampilkan dalam bentuk web sehingga bisa memudahkan wisatawan untuk mengakses informasi.

2. Secara keseluruhan, masih terdapat limitasi pada sistem yaitu sistem masih belum mampu memberikan hasil klasifikasi ulasan dengan tingkat akurasi yang tinggi. Terdapat perbedaan nilai akurasi dari setiap objek wisata. Hal ini disebabkan oleh pengaruh karakteristik data ulasan yang diuji dan jumlah data latih yang digunakan.

3. Berdasarkan hasil sentimen analisis yang dilakukan pada beberapa objek wisata Kalimantan Barat, objek wisata Kalimantan Barat termasuk ke dalam kategori yang positif. Performa metode Naive Bayes menunjukan bahwa nilai fl-score kelas positif pada setiap objek wisata lebih tinggi dibanding kelas netral dan negatif. Hal ini disebabkan karena banyaknya ulasan positif yang diberikan wisatawan terhadap objek wisata Kalimantan Barat.

4. Berdasarkan hasil pengujian fungsionalitas sistem yang dilakukan pada Dinas Kepemudaan, Olahraga dan Pariwisata Provinsi Kalimantan Barat sistem mampu menjalankan fungsi-fungsinya sesuai rancangan yang telah dibuat.
5. Setelah dilakukan pengujian antarmuka sistem kepada 40 responden, antarmuka sistem Sentiment Analisis Objek Wisata Kalimantan Barat memperoleh nilai $84,85 \%$ masuk kedalam kategori baik sekali.

\section{REFERENSI}

[1] Wilianto, L., Pudjiantoro, T. H., \& Umbara, F. R. 2017. Analisis Sentimen Terhadap Tempat Wisata Dari Komentar Pengunjung Dengan Menggunakan Metode Naive Bayes Classifier Studi Kasus Jawa Barat. Jurnal Prosiding Snatif Vol. 4.

[2] Liu, B. 2012. Sentiment analysis and opinion mining. Synthesis lectures on human language technologies. California: Morgan \& Claypool Publishers.

[3] Kim, S. B., Han, K. S., Rim, H. C., \& Myaeng, S. H. 2006. "Some effective techniques for naive bayes text classification." IEEE transactions on knowledge and data engineering, 18(11), 1457 1466.

[4] Gumelar. 2016. Implementasi Metode Naive Bayes Classifier Untuk Klasifikasi dan Analisis Sentimen pada Sistem Pengaduan RSUD Majalengka. Bandung: Universitas Komputer.

[5] Wardani, F., K. 2019. Analisis Sentimen untuk Pemeringkatan Popularitas Situs Belanja Online di Indonesia Menggunakan Metode Naive Bayes (Studi Kasus Data Sekunder). Surabaya: Institut Bisnis dan Informatika STIKOM.

[6] Harijiatno, S., D. (2019). Analisis Sentimen pada Twitter Menggunakan Multinominal Naive. Bayes. Yogyakarta: Universitas Sanata Dharma.

[7] Gunawan, B., Pratiwi, H. S., \& Pratama, E. E. 2018. Sistem Analisis Sentimen pada Ulasan Produk Menggunakan Metode Naive Bayes. Jurnal Edukasi \& Penelitian Informatika Vol. 4 No.2

[8] Somantri, O \& Dairoh, D. 2019. Analisis Sentimen Penilaian Tempat Tujuan Wisata Kota Tegal Berbasis Text Mining. Jurnal Edukasi \& Penelitian Informatika Vol 5 No 2.

[9] Siswanto. 2012. Sistem Informasi Geografis Objek Wisata Menggunakan Google MAPS API Studi Kasus Kabupaten Mojokerto. Surabaya: Institut Teknologi Sepuluh Nopember.

[10] Feldman, R., \& Sanger, J. 2007. Text Mining Handbook: Advanced Approaches in Analyzing Unstructured Data. New York: Cambridge University Press.

[11] Stehman, S., V. (1997). Selecting and interpreting measures of thematic classification accuracy. Remote Sensing of Environment 62(1):77-89

[12] Powers, D. M. W. (2007). Evalution: From Precision, Recall and F-Factor to ROC, Informedness, Markedness \& Correlation. Journal Of Machine Learning Technologies 2(1): 37-63

[13] Kamal, A. F., \& Widjajanto, B. 2017. Text Mining Untuk Analisa Sentiment Ekspedisi Jasa Pengiriman Barang Menggunakan 
Metode Naive Bayes Pada Aplikasi J\&T Express. Semarang: Universitas Dian Nuswantoro

[14] Samuel, A. L. (1959). Some Studies in Machine Learning Using the Game of Checkers. IBM Journal 3(3): 535-554

[15] Hendini, A. 2016. Pemodelan UML Sistem Informasi Monitoring Penjualan dan Stok Barang Studi Kasus: Distro Zhezha Pontianak. Jurnal Khatulistiwa Informatika Vol. IV No. 2

[16] Fridayanthie, E. W. \& Mahdiati, T. 2016. Rancang Bangun Sistem Informasi permintaan ATK Berbasis Intranet (Studi Kasus: Kejaksaan Negeri Bangkasbitung). Jurnal Khatulistiwa Informatika, Vol. IV, No. 2. 